\title{
High-resolution crystal structure of Z-DNA in complex with $\mathrm{Cr}^{3+}$ cations
}

\author{
Pawel Drozdzal • Miroslaw Gilski • Ryszard Kierzek • \\ Lechoslaw Lomozik $\cdot$ Mariusz Jaskolski
}

Received: 19 December 2014 / Accepted: 23 January 2015 / Published online: 17 February 2015

(C) The Author(s) 2015. This article is published with open access at Springerlink.com

\begin{abstract}
This work is part of our project aimed at characterizing metal-binding properties of left-handed Z-DNA helices. The three $\mathrm{Cr}^{3+}$ cations found in the asymmetric unit of the $\mathrm{d}(\mathrm{CGCGCG})_{2}-\mathrm{Cr}^{3+}$ crystal structure do not form direct coordination bonds with atoms of the Z-DNA molecule. Instead, the hydrated $\mathrm{Cr}^{3+}$ ions are engaged in outer-sphere interactions with phosphate groups and O6 and N7 guanine atoms of the DNA. The $\mathrm{Cr}^{3+}(1)$ and $\mathrm{Cr}^{3+}(2)$ ions have disordered coordination spheres occupied by six water molecules each. These partial-occupancy chromium cations are 2.354(15) $\AA$ apart and are bridged by three water molecules from their hydration spheres. The $\mathrm{Cr}^{3+}(3)$ cation has distorted square pyramidal geometry. In addition to the high degree of disorder of the DNA backbone, alternate conformations are also observed for the deoxyribose and base moieties of the G2 nucleotide. Our work illuminates the question of conformational flexibility of Z-DNA and its interaction mode with transition-metal cations.
\end{abstract}

Keywords Z-DNA $\cdot$ Chromium $\cdot$ X-ray crystallography

An Interactive 3D Complement page in Proteopedia is available at: http://proteopedia.org/wiki/index.php/Journal:JBIC:29.

Electronic supplementary material The online version of this article (doi:10.1007/s00775-015-1247-5) contains supplementary material, which is available to authorized users.

P. Drozdzal · M. Gilski · L. Lomozik · M. Jaskolski $(\bowtie)$

Faculty of Chemistry, A. Mickiewicz University, Umultowska 89b, 61-614 Poznan, Poland

e-mail: mariuszj@amu.edu.pl

M. Gilski · R. Kierzek · M. Jaskolski

Institute of Bioorganic Chemistry, Polish Academy of Sciences,

Noskowskiego 12/14, 61-704 Poznan, Poland

\begin{abstract}
Abbreviations
Spm Spermine

Spk Sperminium tetracation

$\mathrm{Put}^{2+}$ Putrescinium dication
\end{abstract}

\section{Introduction}

Trivalent chromium, a $\mathrm{d}^{3}$ cation, is poorly taken up by living cells. The $\mathrm{Cr}^{3+}$ ions are the final product of in vivo $\mathrm{Cr}^{6+}$ metabolism. However, $\mathrm{Cr}^{3+}$ in contrast to $\mathrm{Cr}^{6+}$ can form coordination complexes with macromolecules in the cells [1-3]. In vitro biochemical experiments have shown that exposure of cells to $\mathrm{Cr}^{6+}$ yields binary $\left(\mathrm{DNA}-\mathrm{Cr}^{3+}\right.$ ) and ternary (DNA- $\mathrm{Cr}^{3+}$-ligand) adducts, DNA crosslinks, as well as oxidative DNA lesions [2, 3]. The DNA- $\mathrm{Cr}^{3+}$ complexes are most abundant during in vitro $\mathrm{Cr}^{6+}$ reduction and are less mutagenic than the ternary adducts. It was also found that the $\mathrm{Cr}^{3+}$ ions decrease the fidelity of DNA polymerase [4]. Several attempts have been made to explain the nature of the DNA- $\mathrm{Cr}^{3+}$ interactions. Phosphate groups and/or the N7 guanine atoms have been indicated as the interaction sites in DNA- $\mathrm{Cr}^{3+}$ adducts [2, 5-8]. Some nucleotide- $\mathrm{Cr}^{3+}$ and DNA-[Cr(Schiff base) $]$ complexes were characterized by different techniques, such as ${ }^{31} \mathrm{P}$ NMR, EPR, UV-Vis and IR spectroscopy; however, those studies provided little, if any, precise structural data $[9,10]$. Structures of phosphate-based DNA-Cr ${ }^{3+}$ adducts have also been proposed [11]. Despite the interest in DNA$\mathrm{Cr}^{3+}$ interactions in biological systems, the existing literature provides detailed crystallographic structural data for only two, low-resolution DNA- $\mathrm{Cr}^{3+}$ :DNA polymerase- $\beta$ complexes, PDB 1zqe (3.7 ̊) [12] and 1huz (2.6 ̊) [13]. For these two structures, direct interactions of $\mathrm{Cr}^{3+}$ with the DNA phosphates were described. In particular, no 
structures of Z-DNA-Cr ${ }^{3+}$ complexes have been deposited in the PDB [14] or the NDB [15] databases.

Left-handed duplexes of Z-DNA with the self-complementary $\mathrm{d}(\mathrm{CGCGCG})$ sequence are remarkable for their potential to form crystals that diffract X-rays to very high resolution. We have used those crystals to obtain accurate information about the geometrical parameters characterizing the coordination of $\mathrm{Cr}^{3+}$ ions by left-handed Z-DNA. In the present study, using high-resolution crystallographic data, we describe the coordination geometry of three hydrated $\mathrm{Cr}^{3+}$ ions and their outer-sphere interactions with a highly disordered Z-DNA chain in a d(CGCGCG $)_{2}-\mathrm{Cr}^{3+}$ complex. To the best of our knowledge, a double-conformation guanine base ring is also reported for the first time in any Z-DNA structure.

\section{Materials and method}

Oligonucleotide synthesis, purification and crystallization

A DNA hexamer with the d(CGCGCG) sequence was synthesized on an Applied Biosystems DNA/RNA synthesizer using phosphoramidite chemistry. The methods of deprotection and purification of the oligodeoxynucleotides have been described previously [16]. A $1.5 \mathrm{mM}$ water solution of the DNA oligonucleotide was annealed at $338 \mathrm{~K}$ for 12 min to form a DNA duplex. Single crystals of the DNA were grown at $292 \mathrm{~K}$ by the hanging-drop vapor diffusion method by mixing $2 \mu \mathrm{l}$ of nucleic acid solution and $2 \mu \mathrm{l}$ of precipitating solution containing $10 \%(\mathrm{v} / \mathrm{v})( \pm) 2$-methyl2,4-pentanediol (MPD), $40 \mathrm{mM}$ sodium cacodylate, $\mathrm{pH}$ $6.0,80 \mathrm{mM} \mathrm{KCl}, 12 \mathrm{mM} \mathrm{NaCl}$ and $12 \mathrm{mM}$ sperminium tetrachloride. The drops were equilibrated against $0.5 \mathrm{ml}$ of $35 \%(\mathrm{v} / \mathrm{v})$ MPD. The crystals appeared within 1 week and grew to the dimensions of $0.2 \times 0.1 \times 0.1 \mathrm{~mm}$. The best crystals were used for metal ion soaking. For metal soaking, the crystals were placed for several days in $2 \mu \mathrm{l}$ of the reservoir solution mixed with $2 \mu \mathrm{l}$ of $5 \mathrm{mM}\left[\mathrm{Cr}\left(\mathrm{H}_{2} \mathrm{O}\right)_{6}\right] \mathrm{Cl}_{3}$.

Data collection, structure solution and refinement

$\mathrm{X}$-Ray diffraction data for $\mathrm{Cr}^{3+}$-soaked crystals were collected to the resolution of $0.97 \AA$ at the BESSY synchrotron beamline 14.2 in Berlin (Table 1). The crystal was vitrified in a stream of cold nitrogen gas at $100 \mathrm{~K}$. The mother liquor served as a cryoprotectant solution. The data were recorded in four passes, using different crystal-to-detector distances and exposure times to ensure reliable measurement of the high-resolution data and of the strong low-resolution reflections, and to avoid oversaturation of the MAR225 detector. The crystal-to-detector distances, the corresponding maximum resolution, oscillation and the numbers of images in
Table 1 Data collection and refinement statistics

\begin{tabular}{|c|c|}
\hline Data collection & $\mathrm{d}(\mathrm{CGCGCG})_{2}-\mathrm{Cr}^{3+}$ \\
\hline Radiation source & 14.2 BESSY Berlin \\
\hline Wavelength $(\AA)$ & 0.9184 \\
\hline Temperature (K) & 100 \\
\hline Space group & $P 2{ }_{1}{ }_{1} 2_{1}$ \\
\hline Cell dimensions $(\AA)$ & $a=18.14, b=30.44, c=42.94$ \\
\hline Resolution range $(\AA)$ & $24.83-0.97(1.00-0.97)^{\mathrm{a}}$ \\
\hline Number of reflections & $14,037^{\mathrm{b}} / 26,535^{\mathrm{c}}$ \\
\hline Completeness $(\%)$ & $98.4(93.2)^{\mathrm{c}}$ \\
\hline Redundancy & $2.53(2.14)^{\mathrm{c}}$ \\
\hline$<I / \sigma I>$ & $24.85(2.05)^{\mathrm{c}}$ \\
\hline$R_{\text {merge }}^{\mathrm{d}}(\%)$ & $1.6(43.2)^{\mathrm{c}}$ \\
\hline Wilson B-factor $\left(\AA^{2}\right)$ & 4.87 \\
\hline \multicolumn{2}{|l|}{ Refinement } \\
\hline Refinement program & SHELXL \\
\hline Resolution $(\AA)$ & $24.83-0.97$ \\
\hline No. of reflections in working set & $13,028^{\mathrm{b}} / 24,677^{\mathrm{c}}$ \\
\hline No. of reflections in test set & $1009^{b} / 1856^{c}$ \\
\hline$R / R_{\text {free }}^{\mathrm{e}}(\%)$ & $14.47^{\mathrm{c}} / 18.49^{\mathrm{c}}$ \\
\hline $\begin{array}{l}\text { No. of atoms (nucleic acid/metal/ } \\
\text { solvent) }\end{array}$ & $240 / 3 / 67$ \\
\hline $\begin{array}{l}<B_{\text {eq }}>\left(\AA^{2}\right) \text { (nucleic acid chain } \\
\mathrm{A} / \mathrm{B} / \mathrm{metal} / \text { solvent })\end{array}$ & $17.5 / 13.4 / 13.7 / 23.7$ \\
\hline \multicolumn{2}{|l|}{ R.m.s. deviations from ideal } \\
\hline Bond lengths $(\AA)$ & 0.019 \\
\hline Bond angles $\left({ }^{\circ}\right)$ & 1.93 \\
\hline \multicolumn{2}{|c|}{ a Values in parentheses correspond to the last resolution shell } \\
\hline \multicolumn{2}{|l|}{ b Bijvoet pairs merged } \\
\hline \multicolumn{2}{|l|}{${ }^{c}$ Bijvoet pairs separate } \\
\hline \multicolumn{2}{|c|}{$\begin{array}{l}\mathrm{d} R_{\text {merge }}=\Sigma_{h} \Sigma_{j}\left|I_{j}^{h}-\left\langle I^{h}\right\rangle\right| / \Sigma_{h} \Sigma_{j} I_{j}^{h} \text {, where } I_{j}^{h} \text { is the intensity of } \\
\text { observation } j \text { of reflection } h\end{array}$} \\
\hline \multicolumn{2}{|c|}{$\begin{array}{l}\text { e } R=\Sigma_{h}|| F_{\mathrm{o}}|-| F_{\mathrm{c}}|| / \Sigma_{h}\left|F_{\mathrm{o}}\right| \text { for all reflections, where } F_{\mathrm{o}} \text { and } F_{\mathrm{c}} \text { are } \\
\text { observed and calculated structure factors. } R_{\text {free }} \text { is calculated analo- } \\
\text { gously for a random subset of reflections excluded from the refine- } \\
\text { ment }\end{array}$} \\
\hline
\end{tabular}

the individual passes were (1) $350 \mathrm{~mm}, 2.97 \AA, 1^{\circ}, 100$; (2) $250 \mathrm{~mm}, 2.20 \AA, 1^{\circ}, 100$; (3) $140 \mathrm{~mm}, 1.39 \AA, 1^{\circ}, 110$; (4) $70 \mathrm{~mm}, 0.97 \AA, 1^{\circ}, 110$, respectively. Detailed statistics of the final merged data set are listed in Supplementary Table S1. The diffraction data were indexed, integrated and scaled using the $X D S$ package [17]. The X-ray data statistics are summarized in Table 1 . The structure was solved by molecular replacement using PHASER [18]. The DNA part of the PDB structure 4hig, corresponding to our earlier model of a d(CGCGCG) $)_{2}-\mathrm{Spk}-\mathrm{Mn}^{2+}$ complex [16], was used as a molecular probe. At the initial stages of the refinement, the model was refined using REFMAC5 [19] from the CCP4 program suite [20]. Later, anisotropic refinement with SHELXL [21] was performed using the full resolution of the diffraction data. The anomalous signal, clearly visible 
Fig. 1 Stereoview of the $\mathrm{d}(\mathrm{CGCGCG})_{2}-\mathrm{Cr}^{3+}$ structure with anomalous difference map for the three $\mathrm{Cr}^{3+}$ cations (purple spheres). The map is contoured at $6.5 \sigma$. Note the alternate conformations (I, green; II, orange) along the DNA chains
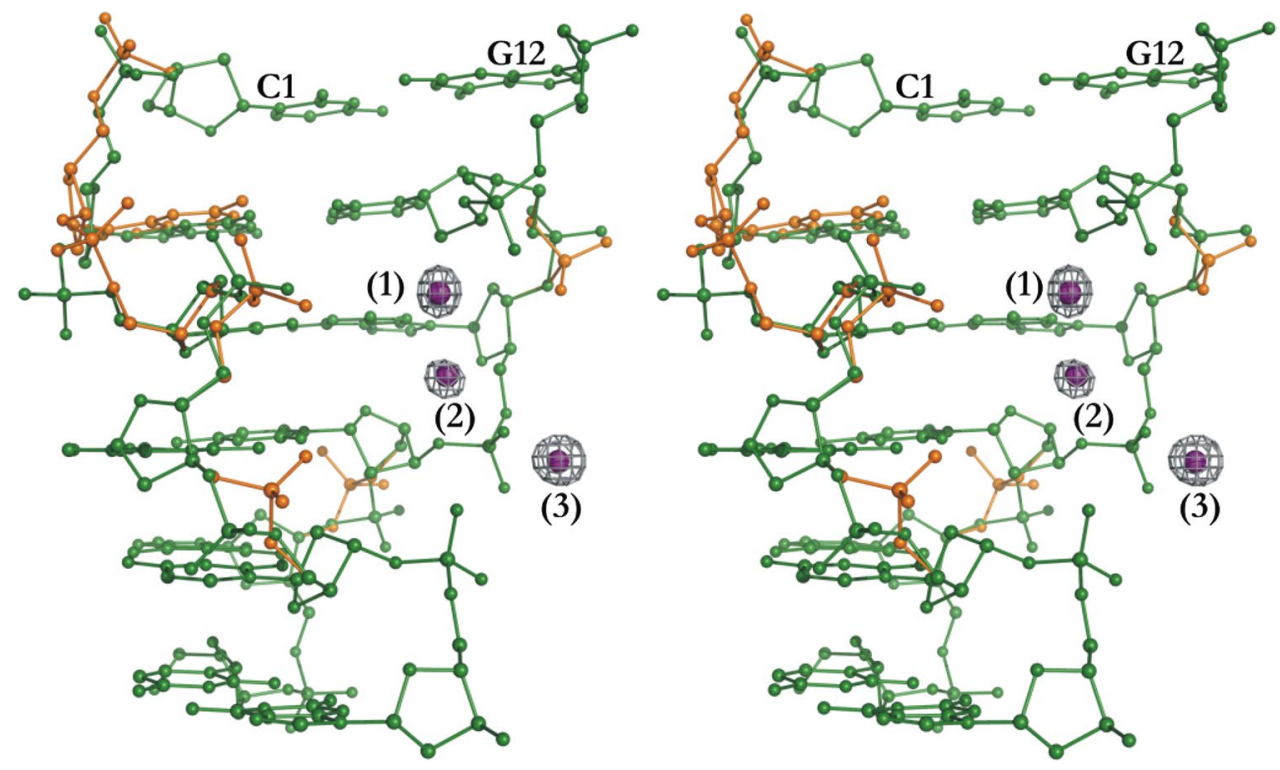

in the diffraction data (Supplementary Table S1), reflects the imaginary component $\left(f^{\prime \prime}\right)$ of the anomalous scattering of the chromium cation (1.028 electrons) at the wavelength of $0.9184 \AA$ [22]. Therefore, the structure-factor refinement was carried out with Bijvoet pairs unmerged. The Flack parameter is $-0.08(9)$, confirming the obvious fact that the absolute structure has been determined correctly.

After each round of 50 cycles of CGLS (conjugategradient least-squares) minimization, the COOT [23] program was used for visualization of electron density maps and manual rebuilding of the atomic model. The occupancies of the DNA moieties in alternative conformations were refined with their sum constrained to unity. Water molecules were added to the model based on $m F o-D F c$ electron density and stereochemical considerations. There are four close pairs of water molecules with combined occupancy of 1.0. The remaining water sites were classified as fully (11) or partially (52) occupied. Ordered water molecules in the coordination sphere of a given $\mathrm{Cr}^{3+}$ ion have the same occupancy as the central atom. Hydrogen atoms were added at their expected positions only to DNA atoms and refined isotropically using the "riding" option.

The model was validated using the free $R$ test [24] and the $N u$ Check program [25]. $\sim 7 \%$ of all reflections were selected at random and set aside for $R_{\text {free }}$ calculations. The test reflections were included in the work set during the final rounds of refinement. Most of the stereochemical restrains for the DNA moieties were taken from Clowney et al. [26], Gelbin et al. [27] and Parkinson et al. [28]. However, the target values for the $\mathrm{C} 4-\mathrm{N} 9-\mathrm{Cl}^{\prime}\left[129.0(7)^{\circ}\right]$ and C8-N9-C1' $\left[124.5(7)^{\circ}\right]$ exocyclic angles in syn purines, which seem to be inadequate in the above dictionaries, were taken from the ultrahigh-resolution Z-DNA-Spm structure $(0.55 \AA$; PDB $3 \mathrm{p} 4 \mathrm{j})$ reported by Brzezinski et al.
[29]. The $3 \mathrm{p} 4 \mathrm{j}$ structure was also used for restraining the $\mathrm{O}-\mathrm{P}-\mathrm{O}$ valence angles in a conformation-dependent manner [30]. At the conclusion of the refinement, one cycle of full-matrix least-squares minimization was calculated with all reflections, but no restraints included to estimate the standard uncertainties (e.s.u.) of the structural and all refined parameters.

The coordinates of the $\mathrm{Cr}^{3+}(1), \mathrm{Cr}^{3+}(2)$ and $\mathrm{Cr}^{3+}(3)$ ions coincide with the most prominent peaks in the anomalous difference Fourier map at 15.0, 10.0 and $16.1 \sigma$, respectively (Fig. 1). The pseudorotation amplitude $\left(\tau_{\mathrm{m}}\right)$ and phase angle $(P)$ of the DNA furanose rings as well as their deviations from the ideal (cyclopentane) model were calculated by the method of Jaskolski [31] (Supplementary Table S2). The Z-DNA helical parameters were calculated using 3DNA [32] and the figures were generated with $P y M o l$ [33].

\section{Results}

Quality of the results

The estimated standard uncertainties of fully occupied DNA atomic positions are $0.017-0.078 \AA$ (C atoms), 0.015-0.047 ̊ (N), 0.011-0.129 ̊ (O) and 0.009-0.018 $\AA$ (P). The positional uncertainties for the metal cations are $0.012,0.021$ and $0.012 \AA$ for $\mathrm{Cr}^{3+}(1), \mathrm{Cr}^{3+}(2)$ and $\mathrm{Cr}^{3+}(3)$, respectively.

Overall structure and helical parameters

The asymmetric unit of the complex contains one $\mathrm{d}(\mathrm{CGCGCG})_{2}$ Z-DNA duplex. The $\mathrm{d}\left(5^{\prime}\right.$-CGCGCG- $\left.3^{\prime}\right)$ nucleotides of chain $A$ are numbered $1-6$, and the 
complementary d( $3^{\prime}$-GCGCGC-5') nucleotides of chain B are numbered $12-7$. The phosphate groups are only present at the internucleotide linkages. The free $5^{\prime}-\mathrm{OH}$ and $3^{\prime}-\mathrm{OH}$ groups are not phosphorylated. The general structural parameters of the DNA double helix in the complex classify it into the Z-DNA family of duplexes. The major (I) and minor (II) conformations of the G2 nucleotide have C3'-endo sugar puckers, with pseudorotation angles of 35.7 and $12.6^{\circ}$, respectively. Different pseudorotation angles are also observed at $\mathrm{C} 3, P=154.7^{\circ}$ (I) and $P=144.3^{\circ}$ (II), although both conformations are in the $\mathrm{C} 2^{\prime}$-endo range. The sugar pucker of $\mathrm{C} 11$ has the pseudorotation angle of $142.8^{\circ}$, classifying it as $\mathrm{C}^{\prime}$-exo. The $3^{\prime}$-terminal nucleotides G6 and G12 have $\mathrm{C} 2$ '-endo sugar pucker. A comparison of the helical parameters and geometry of the present Z-DNA- $\mathrm{Cr}^{3+}$ complex and the previously reported Z-DNA structures is included in Supplementary Table S3.

\section{Disorder of the DNA molecule}

A characteristic feature of the $\mathrm{d}(\mathrm{CGCGCG})_{2}-\mathrm{Cr}^{3+}$ structure is a high degree of disorder of the DNA chains. Double conformations are observed at the internucleotide phosphate linkages $\mathrm{C} 1-\mathrm{G} 2$, G2-C3, C3-G4, G4-C5, G8-C9 and G10-C11 (Fig. 1). These alternate conformations, designated as I/II, have occupancies of 54/46, 54/46, 69/31, $44 / 56,66 / 34$ and $78 / 22 \%$, respectively. In addition, the electron density map clearly shows alternative positions for both the base and deoxyribose rings of the G2 nucleotide (Fig. 2). The base atoms of G2 are translated by up to $1.66 \AA$ Aetween the two states. The hydrogen bond lengths for the two pairs, G2(I).C11 and G2(II).C11, differ from the distances in the canonical Watson-Crick C.G base pair [34]. The $\mathrm{N} 2 \cdots \mathrm{O} 2, \mathrm{~N} 1 \cdots \mathrm{N} 3$ and $\mathrm{O} 6 \cdots \mathrm{N} 4 \mathrm{H}-$ bond distances are shorter in the G2(I).C11 pair [2.742(28), 2.702(28) and 2.517(32) $\AA$ ] and longer in the G2(II).C11 pair [3.006(27), 3.25(14) and 3.374(90) $\mathrm{A}$ ].

The disordered phosphate groups have $\mathrm{Z}_{\mathrm{I}}$ and $\mathrm{Z}_{\mathrm{II}}$ conformation for the alternative positions. $Z_{\mathrm{II}}$ conformation of the nucleotide fragments can be attributed to $\mathrm{G} 2$ (I) $\left(\zeta=59.2^{\circ}\right)$, G4(I) $\left(61.9^{\circ}\right)$, G8(II) $\left(73.3^{\circ}\right)$ and G10(I) $\left(74.7^{\circ}\right)$. The $Z_{\text {II }}$ conformations are stabilized by hydrogen bonds between a phosphate oxygen atom and water molecules form the coordination spheres of the $\mathrm{Cr}^{3+}$ cations, as well as by contacts with symmetry-related Z-DNA helices in the crystal lattice.

The presence of the double-conformation G2 nucleotide causes significant distortions of the helical parameters for the two dinucleotide pairs, C1G2-C11G12 and G2C3G10C11, as well as of the average values for the entire duplex (tip and inclination; Supplementary Table S2) [32]. The helical parameters shift/tilt/ $x$-displacement have the following values: -0.04 and $0.23 \AA / 0.84$ and $2.39 \%-48.89$

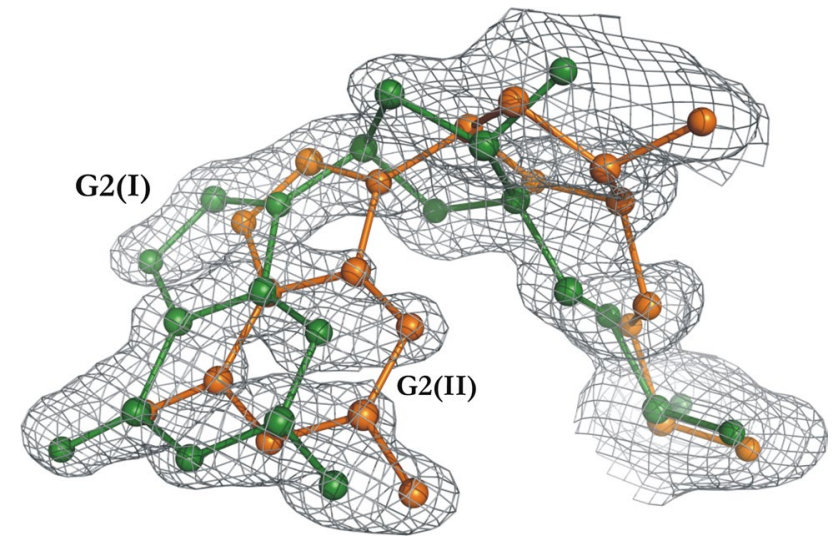

Fig. 2 A portion of the Z-DNA duplex in the d(CGCGCG $)_{2}-\mathrm{Cr}^{3+}$ complex at the $\mathrm{G} 2$ nucleotide with two alternative conformations (I, green; II, orange) shown in $2 m F o-D F c$ map contoured at $1.0 \sigma$

and $-31.99 \AA$, for the pairs of dinucleotides C1G2(I)C11G12 and C1G2(II)-C11G12, respectively. For the dinucleotide pair C3G4-C9G10, there is a difference in the width of the minor groove (after subtraction of $5.8 \AA$ for the combined radii of the phosphorus atoms) between conformations $\mathrm{Z}_{\mathrm{I}}(7.2 \AA)$ and $\mathrm{Z}_{\mathrm{II}}(6.0 \AA)$.

Coordination of the $\mathrm{Cr}^{3+}$ cations and crystal packing

The $\mathrm{Cr}^{3+}(1), \mathrm{Cr}^{3+}(2)$ and $\mathrm{Cr}^{3+}(3)$ ions have partial occupancies of 35, 26 and $40 \%$, respectively (Fig. 1). The $\mathrm{Cr}^{3+}(1)$ and $\mathrm{Cr}^{3+}(2)$ cations, which are unexpectedly only 2.354(15) $\AA$ apart, were treated as separate individual ions during the refinement. It was not possible to unambiguously correlate their partial populations as alternatives within the networks of partially occupied water and disordered DNA fragments. In conclusion, despite their partial occupancies, the possibility of a direct interaction between the $\mathrm{Cr}^{3+}(1)$ and $\mathrm{Cr}^{3+}(2)$ ions in the crystal lattice cannot be excluded, especially in view of the bridging water molecules. A similarly short contact [2.394(1) $\AA]$ between $\mathrm{Cr}^{3+}$ ions was found in a $\mu$-methylene complex, as reported by Noh et al. [35].

The coordination spheres of $\mathrm{Cr}^{3+}(1)$ and $\mathrm{Cr}^{3+}(2)$ contain six water molecules each (Fig. 3a; Table 2). The $\mathrm{Cr}^{3+}(1)$ and $\mathrm{Cr}^{3+}(2)$ ions are bridged by three water molecules from their coordination spheres, one of which (Wat1) is split into two sites. The hydration patterns of $\mathrm{Cr}^{3+}(1)$ and $\mathrm{Cr}^{3+}(2)$ are irregular and difficult to define. The detailed geometry of the coordination spheres of $\mathrm{Cr}^{3+}(1)$ and $\mathrm{Cr}^{3+}(2)$ is summarized in Table 2. The water molecules from the hydration spheres of $\mathrm{Cr}^{3+}(1)$ and $\mathrm{Cr}^{3+}(2)$ form numerous hydrogen bonds with the DNA atoms. The water molecules from the coordination sphere of $\mathrm{Cr}^{3+}(1)$ are hydrogen bonded to OP2_G4(I), OP1_G12, OP2_G12, and to N7_G10 $(x-1$, 


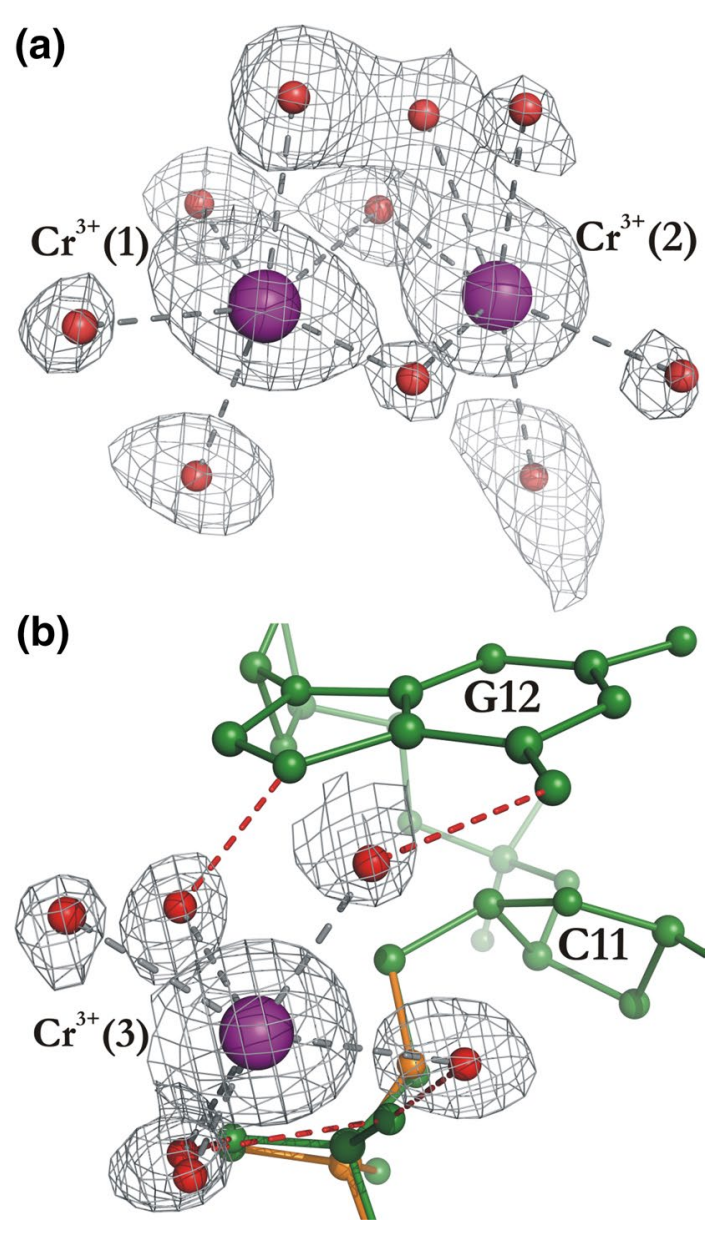

Fig. 3 a The coordination spheres of the hydrated $\mathrm{Cr}^{3+}(1)$ and $\mathrm{Cr}^{3+}(2)$ ions. The $2 m F o-D F c$ map is contoured at the $1.0 \sigma$ level. $\mathbf{b}$ The distorted square pyramidal coordination sphere of the $\mathrm{Cr}^{3+}(3)$ cation. The $2 \mathrm{mFo}-\mathrm{DFc}$ map is contoured at the $1.0 \sigma$ level. Water molecules are represented by red spheres. The coordination and hydrogen bonds are represented by gray and red dashed lines, respectively

$y, z), \mathrm{OP} 2(\mathrm{I}) \_\mathrm{C} 11^{\mathrm{ii}}(x-1 / 2,3 / 2-y, 1-z), \mathrm{OP} 1(\mathrm{II}) \_\mathrm{C} 11^{\mathrm{ii}}$ from symmetry-related molecules. The hydration sphere of the $\mathrm{Cr}^{3+}(2)$ ion is engaged in contact with OP1_G6, and with N7_G10 $0^{\mathrm{i}}$ OP1(II)_C9 ${ }^{\mathrm{i}}, \mathrm{OP} 1(\mathrm{II}) \_\mathrm{C} 11^{\mathrm{ii}}, \mathrm{OP} 2(\mathrm{I})+\mathrm{C} 11^{\mathrm{ii}}$ from symmetry-related molecules. Similarly to $\mathrm{Cr}^{3+}(1)$ and $\mathrm{Cr}^{3+}(2)$, also the $\mathrm{Cr}^{3+}(3)$ cation is not coordinated directly by atoms of the nucleic acid. The coordination sphere of $\mathrm{Cr}^{3+}(3)$ is square pyramidal, with five water molecules, one of which (Wat37) is split into two sites (Fig. 3b). The $\mathrm{Cr}^{3+}-\mathrm{OH}_{2}$ bond length ranges for the metal cations $1 / 2 / 3$ are, respectively, 1.59(4)-2.35(4)/1.73(6)-2.41(3)/1.83(5)2.65(5) $\AA$ (Table 2). Water molecules as ligands of $\mathrm{Cr}^{3+}(3)$ form hydrogen bonds with OP1_G6, OP2_G6, and with OP1(I)_C11 $1^{\mathrm{ii}}, \mathrm{OP} 2(\mathrm{I})+\mathrm{C} 11^{\mathrm{ii}}$, O6_G12ii N7_G12ii from a symmetry-related molecule. The distances from the $\mathrm{Cr}^{3+}(3)$ cation to $\mathrm{Cr}^{3+}(1)$ and $\mathrm{Cr}^{3+}(2)$ are 7.007(11) and 6.017(15) ^, respectively. It should be noted that the hydrated $\mathrm{Cr}^{3+}$ cations in the Z-DNA- $\mathrm{Cr}^{3+}$ complex interact via their hydration shells with phosphate groups of the DNA fragments in double conformation.

The crystals of the Z-DNA- $\mathrm{Cr}^{3+}$ complex belong to space group $P 22_{1} 2_{1} 2_{1}$ and have the less common $\mathrm{B}$ type of crystal packing of Z-DNA structures (also called purespermine type), as reported for the first time by Egli et al. [d(CGCGCG) $)_{2}-$ Spm; PDB 1d48] [36]. As described in detail by Brzezinski et al. [29], d(CGCGCG) $)_{2}$ Z-DNA crystallizes into two polymorphic forms (A and $\mathrm{B}$ ) of the same space group and cell parameters, but with different crystal packing. A detailed discussion of the influence of metal and/or polyamine cations, and disorder of Z-DNA on crystal packing can be found in Brzezinski et al. [29], Schuerman et al. [37] and Harper et al. [38].

Stacking interactions

Except for the G2(II) C C11 base pair, the DNA duplex in the $\mathrm{d}(\mathrm{CGCGCG})_{2}-\mathrm{Cr}^{3+}$ complex has the structure of stacking interactions typical of the Z-DNA form. For the G2(I).C11 and G2(II).C11 base pairs, important stacking differences are noted when compared with other duplexes with the $\mathrm{d}(\mathrm{CGCGCG})_{2}$ sequence. The overlap areas of the guanine ring $\mathrm{G} 2$ (including the exocyclic $\mathrm{N}$ and $\mathrm{O}$ atoms) in conformations I and II over the C3 base are 3.75 and $5.99 \AA^{2}$, respectively. For the previously described d(CGCGCG) ${ }_{2}-$ Spk $-\mathrm{Mn}^{2+}$ (PDB 4hig), d(CGCGCG) $)_{2}-\mathrm{Spk}_{-\mathrm{Zn}^{2+}}$ (4hif), $\mathrm{d}(\mathrm{CGCGCG})_{2}-\mathrm{Put}^{2+}-\mathrm{K}^{+}$[39] and d(CGCGCG) $)_{2}-\mathrm{Spm}$ (3p4j) complexes, the analogous values of the overlap area for the same bases were $4.36,5.24,4.76$, and $4.76 \AA^{2}$, respectively.

\section{Hydration}

The $\mathrm{d}(\mathrm{CGCGCG})_{2}-\mathrm{Cr}^{3+}$ complex is similar to other highresolution structures of Z-DNA with regard to the architecture of the hydration shell, which comprises a complicated network of hydrogen bonds that stabilize the molecular packing in the crystal. The asymmetric unit contains 67 water sites. The characteristic features of hydration geometry noted in other Z-DNA crystals, such as the spine of hydration [40], water molecules between N2_G and phosphate $\mathrm{O}$ atoms, two water molecules $\mathrm{H}$-bonded to each O6_G group, or absence of water molecules H-bonded to the N3_G atoms, are also found in the present Z-DNA$\mathrm{Cr}^{3+}$ complex. The positions of two disordered water molecules, Wat 2 and Wat53, are correlated with the alternate conformations of the DNA chain between the G2-C3 and G8-C9 nucleotides, respectively. The G2(I).C11 and G2(II). C11 base pairs have different schemes of hydration. There are no N2 ‥Wat interactions for the G2(I) conformation. Atom O6_G2(I) forms hydrogen bonds with Wat10 
Table 2 Coordination geometry $\left(\AA,^{\circ}\right)$ around the $\mathrm{Cr}^{3+}$ cations

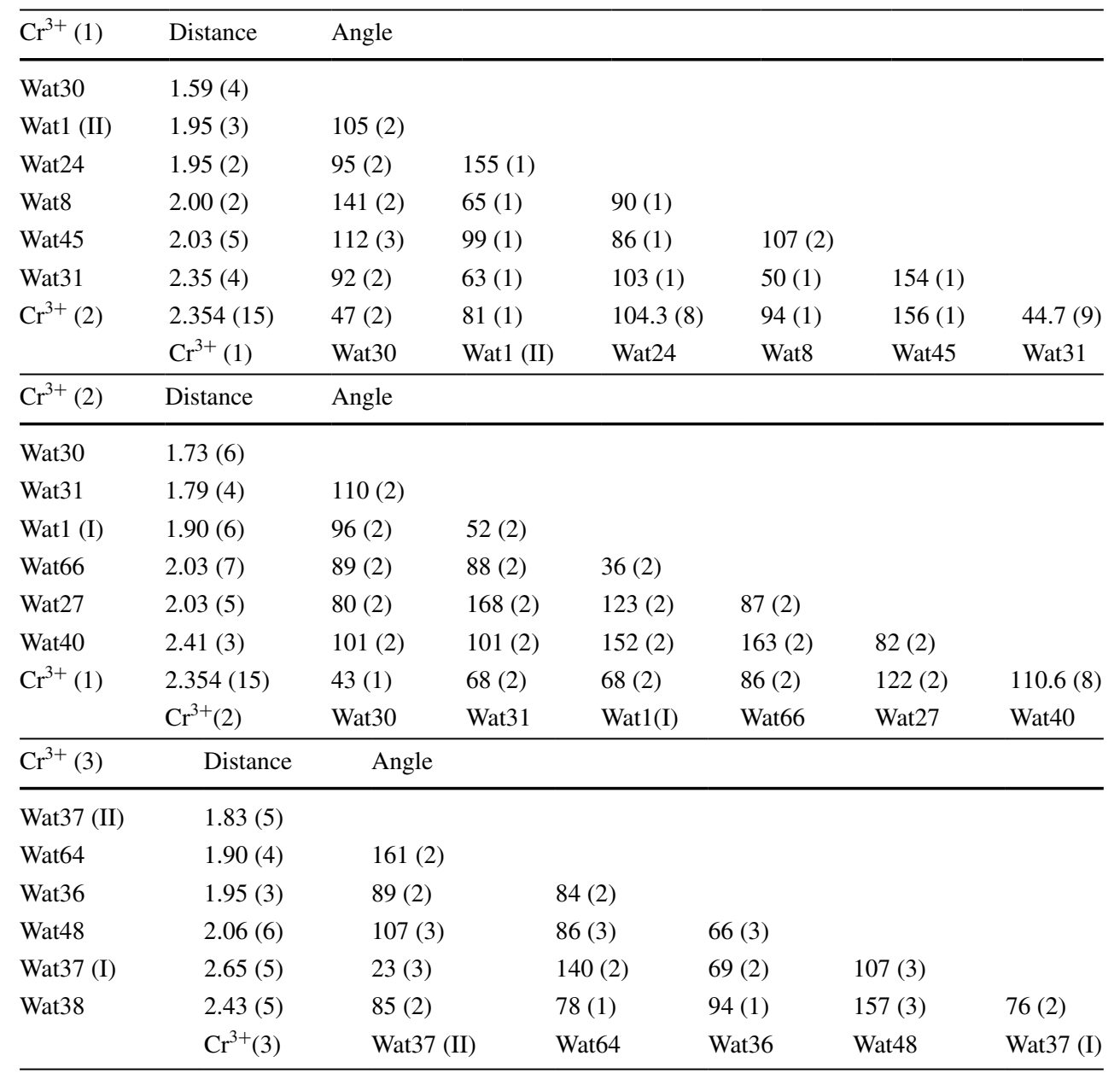

[3.182(48) $\AA]$ and Wat65 [2.560(72) ̊]]. Atom N7_G2(I) is H-bonded to Wat10 [3.143(62) $\AA$ ]. In the alternative conformation, the N2_G2(II) atom forms a hydrogen bond with Wat22 [2.862(45) $⿱$ ] , which bridges it with OP2 C3(II) [2.794(27) $\AA$ ]. There is also a weak H-bond interaction N2_G2(II)...Wat68 [3.366(49) $\AA$ ].

\section{Discussion}

The high-resolution crystal structure of the $\mathrm{d}(\mathrm{CGCGCG})_{2}-$ $\mathrm{Cr}^{3+}$ complex presented in this work shows the presence of three $\mathrm{Cr}^{3+}$ ion sites per one Z-DNA duplex, which do not form any direct coordination bonds with either the guanine N/O atoms or the phosphate groups of the DNA. Only water-mediated contacts between the nucleic acid and the $\mathrm{Cr}^{3+}$ cations are observed. The degree of disorder of the DNA strands in the Z-DNA- $\mathrm{Cr}^{3+}$ complex is comparable with that in the recently presented metaland polyamine-cation free Z-DNA hexamer (PDB 3wbo) [41] and dodecamer (4ocb) [42] structures, and even higher than in the Z-DNA complexes with $\mathrm{Mn}^{2+}$ (4hig) and $\mathrm{Zn}^{2+}$ (4hif) reported by Drozdzal et al. [16] or in d(CGCGCA):d(TGCGCG)-[Ru( $\left.\left.\mathrm{NH}_{3}\right)_{6}\right]^{3+}$ (2hto) [43]. The high degree of disorder in this and similar Z-DNA structures is in stark contradiction to the rigidity of the same chemical molecule (crystallized without metal cations) reported by Brzezinski et al. [29]. In view of the accumulated facts, it seems that the rigidity observed in that ultrahigh-resolution structure (PDB 3p4j) was a fortuitous exception rather than a rule. In addition to alternative positions of the backbone phosphate groups, the present electron density maps also clearly show a double conformation of the $\mathrm{G} 2$ nucleoside. The alternate conformations of $\mathrm{G} 2$ in the Z-DNA- $\mathrm{Cr}^{3+}$ structure resulted in deviations from typical hydrogen bonding and stacking interaction observed for the G2C3-G10C11 base pairs in similar $\mathrm{d}(\text { CGCGCG })_{2}$ structures. Analysis of the positions of the base rings of G2(I) and G2(II) indicates a tendency to keep the DNA strands in favorable contacts with water molecules. The alternative positions of the $\mathrm{G} 2$ nucleotide do not affect the orientation of the complementary $\mathrm{C} 11$ base. The $m F o-D F c$ map for the $\mathrm{C} 11$ nucleotide does not indicate any peaks (even at the $2.5 \sigma$ level) to suggest possible 
alternate positions of the cytosine base, which could be correlated with the G2(I)/(II) conformations. This observation is in contrast to findings based on a high-resolution $(0.96 \AA)$ B-DNA- $\mathrm{Mg}^{2+}$ structure with full base-pair positional heterogeneity (PDB 3u89) [44]. The present structure of the $\mathrm{d}(\mathrm{CGCGCG})_{2}-\mathrm{Cr}^{3+}$ complex confirms the inherent polymorphism in the positions of the DNA atoms and suggests that complementary bases can move independently within the DNA scaffold. Thus, the tendency to maintain the exact Watson-Crick base-pairing geometry with both $\mathrm{G} 2$ conformations is not the predominant factor for the $\mathrm{C} 11$ nucleotide and many other factors, such as stacking interactions, water and/or ligand interactions, as well as crystal packing, should be taken into account when considering the energy balance of a single nucleotide conformation. Moreover, the stable position of the base ring of C11 within the G2(I)/(II).C11 base pair may confirm the crucial role played by water molecules in DNA stabilization [45].

The crystal structure of the $\mathrm{d}(\mathrm{CGCGCG})_{2}-\mathrm{Cr}^{3+}$ complex analyzed in this study has the same packing mode of the Z-DNA helices as the d(CACGIUG) $)_{2}-\left[\mathrm{Co}\left(\mathrm{NH}_{3}\right)_{6}\right]^{3+}$ (PDB 1omk) [37] and d(TGCGCA $)_{2}-\left[\mathrm{Co}\left(\mathrm{NH}_{3}\right)_{6}\right]^{3+}(362 \mathrm{~d})$ structures [38]. Although sperminium tetrachloride was present in the crystallization conditions, the spermin $e^{4+}$ tetracation has not been identified in the electron density maps of the $\mathrm{d}(\mathrm{CGCGCG})_{2}-\mathrm{Cr}^{3+}$ crystal. This suggests either a complete disorder of the entire spermine ${ }^{4+}$ molecule, or its total absence in the crystal structure.

\section{Conclusions}

Our studies of the $\mathrm{d}(\mathrm{CGCGCG})_{2}-\mathrm{Cr}^{3+}$ complex indicate that Z-DNA, especially in complexes with metal cations, has a large potential for conformational flexibility. The present structure, as well as other examples deposited in the PDB, strongly supports the notion that Z-DNA helices should not be regarded as having extremely regular and rigid stereochemistry, in contradiction to the suggestion made by Brzezinski et al. [29]. The d(CGCGCG) $)_{2}-\mathrm{Cr}^{3+}$ structure is an excellent illustration of the flexibility of the Z-DNA molecule, visible in the adoption of multiple conformations (by the phosphate groups and the G2 nucleotide), in response to changes in its electrostatic and hydration environment, caused by the introduction of hydrated metal complexes.

Acknowledgments We thank Jakub Barciszewski for help at the BESSY beamline. MJ is a recipient of a National Science Center grant 2013/10/M/NZ1/00251. RK is a recipient of National Science Center Grants 2011/03/B/NZI/00576, 2011/03/B/ST5/01098 and 2013/08/A/ST5/00295.
Open Access This article is distributed under the terms of the Creative Commons Attribution License which permits any use, distribution, and reproduction in any medium, provided the original author(s) and the source are credited.

\section{References}

1. Cieslak-Golonka M (1995) Polyhedron 15:3667-3689

2. Salnikow K, Zhitkovich A (2008) Chem Res Toxicol 21:28-44

3. Zhitkovich A (2011) Chem Res Toxicol 24:1617-1629

4. Snow ET (1994) Environ Health Perspect 102:41-44

5. Mattagajasingh SN, Misra HP (1996) J Biol Chem 271:33550-33560

6. Watson RT, Desai N, Wildsmith J, Wheeler JF, Kane-Maguire NAP (1999) Inorg Chem 38:2683-2687

7. Arakawa H, Ahmad R, Naoui M, Tajmir-Riahi HA (2000) J Biol Chem 275:10150-10153

8. Vaidyanathan VG, Asthana Y, Nair BU (2013) Dalton Trans 42:2337-2346

9. Rhodes NR, Belmore K, Cassady CJ, Vincent JB (2013) Polyhedron 64:136-141

10. Vaidyanathan VG, Weyhermuller T, Nair BU, Subramanian J (2005) J Inorg Biochem 99:2248-2255

11. Zhitkovich A, Song Y, Quievryn G, Voitkun V (2001) Biochemistry 40:549-560

12. Pelletier H, Sawaya MR (1996) Biochemistry 35:12778-12787

13. Arndt JW, Gong W, Zhong X, Showalter AK, Liu J, Dunlap ChA, Lin Z, Paxson Ch, Tsai M-D, Chan MK (2001) Biochemistry 40:5368-5375

14. Berman HM, Westbrook J, Feng Z, Gilliland G, Bhat TN, Weissig H, Shindyalov IN, Bourne PE (2000) Nucleic Acids Res 28:235-242

15. Narayanan BC, Westbrook J, Ghosh S, Petrov AI, Sweeney B, Zirbel CL, Leontis NB, Berman HM (2013) Nucleic Acids Res 42:D114-D122

16. Drozdzal P, Gilski M, Kierzek R, Lomozik L, Jaskolski M (2013) Acta Cryst D69:1180-1190

17. Kabsch W (2010) Acta Cryst D66:125-132

18. McCoy AJ, Grosse-Kunstleve RW, Adams PD, Winn MD, Storoni LC, Read RJ (2007) J Appl Crystallogr 40:658-674

19. Murshudov GN, Skubák P, Lebedev AA, Pannu NS, Steiner RA, Nicholls R, Winn MD, Long F, Vagin AA (2011) Acta Cryst D67:355-367

20. Winn MD, Ballard CC, Cowtan KD, Dodson EJ, Emsley P, Evans PR, Keegan RM, Krissinel EB, Leslie AGW, McMoy A, McNicholas SJ, Murshudov GM, Pannu NS, Potterton EA, Powell HR, Read RJ, Vagin A, Wilson KS (2011) Acta Cryst D67:235-242

21. Sheldrick GM (2008) Acta Cryst A64:112-122

22. Cromer DT (1983) J Appl Crystallogr 16:437-438

23. Emsley P, Lohkamp B, Scott WG, Cowtan K (2010) Acta Cryst D66:486-501

24. Brünger AT (1992) Nature 355:472-475

25. Feng Z, Westbrook J, Berman HM (1998) Report NDB-407 Rutgers University New Brunswick NJ

26. Clowney L, Jain SC, Srinivasan AR, Westbrook J, Olson WK, Berman HM (1996) J Am Chem Soc 118:509-518

27. Gelbin A, Schneider B, Clowney L, Hsieh S-H, Olson WK, Berman HM (1996) J Am Chem Soc 118:519-529

28. Parkinson G, Vojtechovsky J, Clowney L, Brünger AT, Berman HM (1996) Acta Cryst D52:57-64

29. Brzezinski K, Brzuszkiewicz A, Dauter M, Kubicki M, Jaskolski M, Dauter Z (2011) Nucleic Acids Res 39:6238-6248

30. Kowiel M, Jaskolski M (unpublished work) 
31. Jaskolski M (1984) Acta Cryst A40:364-366. http://cryst.ump. edu.pl/pseudorotation.php. Accessed 18 Dec 2014

32. Lu X-J, Olson WK (2003) Nucleic Acids Res 31:5108-5121

33. DeLano WL (2002) PyMOL. http://www.pymol.org. Accessed 18 Dec 2014

34. Guerra CF, Bickelhaupt FM, Snijders JG, Baerends EJ (2000) J Am Chem Soc 122:4117-4128

35. Noh SK, Heintz RA, Juniuk Ch, Sendlinger SC, Theopold KH (1990) Angew Chem Int Ed Engl 29:775-777

36. Egli M, Williams LD, Gao Q, Rich A (1991) Biochemistry 30:11388-11402

37. Schuerman G, van Hecke K, Meervelt L (2003) Acta Cryst D59:1525-1528

38. Harper A, Brannigan JA, Buck M, Hewitt L, Lewis RJ, Moore MH, Schneider B (1998) Acta Cryst D54:1273-1284
39. Drozdzal P (2013) Ph. D. Thesis, A. Mickiewicz University, Poznan, Poland. http://hdl.handle.net/10593/10090. Accessed 18 Dec 2014

40. Chevrier B, Dock AC, Hartmann B, Leng M, Moras D, Thuong MT, Westhof E (1986) J Mol Biol 188:707-719

41. Chatake T (2013) J Synchrotron Rad 20:864-868

42. Luo Z, Dauter M, Dauter Z (2014) Acta Cryst D70:1790-1800

43. Bharanidharan D, Thiyagarajan S, Gautham N (2007) Acta Cryst F63:1008-1013

44. Maehigashi T, Hsiao Ch, Woods KK, Moulaei T, Hud NV, Williams LD (2012) Nucleic Acids Res 40:3714-3722

45. Westhof E (1990) In: Vasilescu D, Jaz J, Packer L, Pullman B (eds) Water and ions in biomolecular systems-advances in life sciences. Birkhäuser, Basel, pp 11-18 